\title{
Andador, usos e demandas associadas: um estudo de campo sob a perspectiva do Design
}

\author{
Walker, uses and associated demands: a field study from the perspective of Design
}

ARIGONI, Luiza Beck; Mestre em Design; Instituto Nacional de Tecnologia

luizaarigoni@hotmail.com

SILVA, Julio; Doutor em Design; Instituto Nacional de Tecnologia

julio.silva@int.gov.br

COSTA, Diego dos Santos; Mestre em Engenharia da Produção; Instituto Nacional de Tecnologia dscosta.c@gmail.com

RIBEIRO, Liliane; Graduada em Design; Instituto Nacional de Tecnologia

lilianecmribeiro@gmail.com

ZANUTTI, Diego; Graduado em Design de Produto; Instituto Nacional de Tecnologia

srnildiego00g@gmail.com

\section{Resumo}

Andadores são dispositivos de auxílio à marcha, empregados regularmente na reabilitação de condições de saúde de diferentes procedências. O seu uso reduz a carga a ser sustentada pelos membros inferiores, auxilia na manutenção do equilíbrio corporal e permite o deslocamento em pé a partir das capacidades remanescentes ao usuário. Por meio de referencial teórico multidisciplinar e pesquisa de campo com profissionais de reabilitação e usuários de andadores, este estudo investigou demandas relacionadas ao uso dos dispositivos, focando especialmente nos aspectos de interação com o produto e no desempenho de atividades de vida diária. Entre os resultados encontrados estão um maior nível de funcionalidade e independência, especialmente na execução de atividades básicas de vida diária em ambiente domiciliar, mas também limitações importantes, que poderiam ser resolvidas ou minimizadas com o uso de dispositivos assistivos mais alinhados às características das pessoas e dos contextos em que elas vivem.

Palavras Chave: Andadores; funcionalidade; atividades de vida diária.

\begin{abstract}
Walkers are gait assist devices, regularly employed in the rehabilitation of health conditions from different causes. Its use reduces the load to be sustained by the lower limbs, assists in the maintenance of the corporal balance and allows gait performance with the remaining capacities of the user. Through a multidisciplinary theoretical framework and field research with rehabilitation professionals and users of walkers, this study investigated demands related to the use of the devices, focusing especially on the aspects of interaction with the product and on the performance of activities of daily living. Among the findings are: a highest level of functionality and independence, especially in basic home-based activities of daily living, but also important
\end{abstract}


limitations that could be solved by using assistive devices more aligned with the characteristics of the people and the contexts they live.

Keywords: Walker; functionality; activities of daily living.

\section{Introdução}

Andadores são equipamentos de auxílio à marcha, que fornecem suporte ao peso corporal e colaboram no equilíbrio do usuário. Por tais atributos, são empregados amplamente na reabilitação de condições de saúde ${ }^{1}$ de diferentes ordens.

Uma das principais conveniências do uso do andador é a possibilidade do deslocamento em pé, a partir da capacidade remanescente de marcha do indivíduo. Essa mobilidade favorece a manutenção do funcionamento dos diversos sistemas fisiológicos e ajuda na prevenção de condições de saúde relacionadas a baixos níveis de atividade corporal (BATENI \& MAKI, 2005). Por outro lado, o uso do andador vem sendo relacionado ao risco de quedas (BATENI \& MAKI, 2005; BRADLEY \& HERNANDEZ, 2011) e pode levar a restrições em participação social e no envolvimento em atividades. Estudos também demonstram altos índices de abandono de equipamentos de auxílio à marcha, por motivos que incluem a falta atenção às opiniões dos usuários e a insatisfação em relação à performance dos dispositivos (PHILLIPS \& ZHAO, 1993).

Tendências globais, como o envelhecimento demográfico e o aumento na incidência de doenças crônicas, vêm resultando no crescimento das populações com deficiências, incapacidades e mobilidade reduzida (WORLD HEALTH ORGANIZATION [WHO], 2015). Por conseguinte, se amplia a demanda em relação à pesquisa e desenvolvimento no campo interdisciplinar chamado Tecnologia Assistiva, que abrange "produtos, recursos, metodologias, estratégias, práticas e serviços", concebidos com vistas a fomentar a funcionalidade, oportunizar a atividade e a participação a essas populações (BRASIL, 2009).

Esse estudo se insere no campo da Tecnologia Assistiva, a partir da perspectiva do Design. Parte de referencial teórico multidisciplinar e pesquisa de campo, com propósito de investigar demandas relacionadas ao uso de andadores, concentrando-se especialmente em aspectos de interação e no desempenho de atividades de vida diária com os dispositivos.

\section{Funcionalidade e incapacidade}

Sendo a Tecnologia Assistiva uma área frequentada por várias disciplinas, é razoável que existam perspectivas diferentes e mesmo divergentes sobre alguns tópicos. Essa diversidade se faz pertinente diante de temas complexos como a incapacidade, e aumenta as possibilidades de pesquisa e intervenção em prol da funcionalidade.

De acordo com a Organização Mundial da Saúde (OMS), podem ser identificados dois paradigmas distintos em torno da incapacidade: o médico e o social. No paradigma médico, a incapacidade é concebida como um problema individual, que advém de uma condição de saúde. $A$ intervenção tem como objetivo o diagnóstico e a reabilitação, a partir da adaptação do paciente ou, no melhor dos cenários, a sua cura. No paradigma social, por sua vez, a incapacidade é concebida como uma questão política, que advém da insuficiência da sociedade em se adaptar à diversidade e incluir o indivíduo. Adeptos dessa perspectiva argumentam que as pessoas não

\footnotetext{
${ }^{1}$ Condição de saúde é um termo amplo utilizado em referência a doenças crônicas ou agudas, transtornos, lesões e traumas (WHO, 2015b).
} 
experimentariam incapacidades em contextos físicos e sociais adequados e, portanto, sua atuação em prol da funcionalidade visa essa adequação (WHO, 2002).

Compreendendo a relevância e as limitações de ambos os paradigmas, a OMS elaborou a Classificação Internacional de Funcionalidade, Incapacidade e Saúde (CIF) a partir de um paradigma biopsicossocial. Assim sendo, preconiza que fatores biológicos, individuais e sociais estabeleçam interações dinâmicas que influenciam as capacidades de um indivíduo, promovendo a funcionalidade ou gerando incapacidades. Na definição da CIF, funcionalidade é um termo que abrange (1) todas as funções do corpo, sejam elas fisiológicas ou psicológicas; (2) atividades, termo que se refere à execução de tarefas; e participação, que se refere ao envolvimento nas situações da vida. Em contrapartida, o termo incapacidade abrange (1) deficiências, que são "problemas em funções ou estruturas corporais, como um desvio significativo ou perda"; (2) limitações de atividade; e (3) restrições na participação (WHO, 2002).

Os conceitos de funcionalidade e incapacidade estão estreitamente relacionados ao desempenho de atividades de vida diária (AVDs), que são categorizadas conforme seu nível de complexidade: (1) as atividades básicas de vida diária (ABVDs) são relativas à sobrevivência e ao autocuidado. Algumas são funções vegetativas simples, como alimentação, continência e deslocamento, por exemplo, e outras são culturalmente assimiladas, como fazer uso do banheiro, cuidar da aparência e da higiene pessoal; (2) as atividades instrumentais de vida diária (AIVDs) são relativas à gestão da casa e da própria vida. São exemplos de AIVDs a execução de tarefas domésticas, a administração de dinheiro e de medicamentos; e (3) as atividades avançadas de vida diária (AAVDs) são relativas ao envolvimento em situações sociais, laborais e de lazer. Dentre todas as AVDs, essas atividades são as mais complexas, relacionadas com a cultura e a individualidade (MORAES \& CINTRA, 2013; ASSIS, ASSIS \& CARDOSO, 2013).

A mobilidade é uma capacidade determinante para a execução das AVDs, para a funcionalidade e independência de um indivíduo. Ela engloba recursos que permitem a manipulação do meio e o deslocamento individual. A manipulação do meio costuma ser realizada com os membros superiores e é dada por competências de alcance, preensão e pinça. $O$ deslocamento, por sua vez, costuma ser realizado com os membros inferiores e é dado por competências de postura, marcha e transferência postural (MORAES \& CINTRA, 2013).

Outro conceito vinculado ao de funcionalidade é o de reabilitação, definida como "um conjunto de medidas que ajudam indivíduos que experimentam (ou são suscetíveis a experimentar) incapacidades a terem e manterem uma funcionalidade ideal na interação com o ambiente em que estão inseridos" (WHO, 2011, p.99. Tradução nossa ${ }^{2}$ ).

O paradigma biopsicossocial que a OMS tem adotado em suas publicações (WHO, 2002; 2011; 2015; 2015b) evidencia que diferentes contextos possam ter impactos distintos sobre as capacidades de um indivíduo. Por exemplo, uma pessoa com dada deficiência nos membros inferiores poderá ter ou manter parte de sua funcionalidade, se tiver acesso à reabilitação, rede de suporte, tecnologia assistiva alinhada às suas necessidades e ao ambiente físico em que vive etc. Em um contexto desfavorável, essa mesma pessoa tenderá a experimentar diferentes graus de incapacidades. O paradigma biopsicossocial possibilita a observação da funcionalidade e incapacidade em diferentes níveis, e favorece a pesquisa e a atuação por áreas que não são

\footnotetext{
2 "a set of measures that assist individuals who experience, or are likely to experience, disability to achieve and maintain optimal functioning in interaction with their environments"
} 
tradicionalmente ou exclusivamente dedicadas ao trabalho com pessoas com limitações de funcionalidade - como é o caso do Design.

\subsection{Andadores}

Entre os produtos de TA que visam à manutenção da mobilidade individual, estão os dispositivos de auxílio à marcha, como os andadores. Esses equipamentos costumam ser prescritos quando é necessário aumentar a base de apoio do indivíduo; reduzir a carga corporal suportada pelos membros inferiores; ampliar a recepção de informações sensoriais; ajustar a velocidade de marcha; e/ou reduzir desvios do centro gravitacional do corpo (CARVALHO, 2013).

Andadores se caracterizam por suas estruturas metálicas tubulares, que podem ser fixas ou articuladas, e finalizadas em três ou quatro apoios. Os dispositivos podem ser encontrados em três configurações principais, que têm uso prescrito de acordo com as particularidades dos pacientes, e que se distinguem de acordo com o tipo de apoio em relação ao chão (CARVALHO, 2013; MARTINS ET AL., 2011; VAN HOOK ET AL., 2003):

Os modelos com todos os apoios fixos (fig.1 A) são os mais comumente utilizados. Costumam ser recomendados para pacientes que têm pouco equilíbrio ou que precisam reduzir o peso sobre os membros inferiores. Para execução da marcha, o indivíduo deve erguer e posicionar o andador ligeiramente à frente, realizando a passada e repetindo o ciclo, alternando as pernas sucessivamente. Esses modelos são os que oferecem maior estabilidade. Todavia, tendem a comprometer os padrões de marcha e postura do usuário, pela necessidade de erguer o andador, que leva à descontinuidade da passada.

Os modelos com rodas dianteiras e apoios posteriores fixos (fig.1 B) proporcionam uma marcha mais natural em comparação com os andadores com todos os apoios fixos. Em contraponto oferecem menos estabilidade. Em vista disso, costumam ser prescritos para pessoas que tenham força reduzida nos membros superiores, tendência a executar a marcha de maneira acelerada ou a cair para traz.

Os modelos com todos os apoios em forma de rodas, também conhecidos como rollators (fig.1 C e D), são os que oferecem o padrão de marcha mais natural e constante de todas as configurações de andadores. Esses modelos costumam ter sistemas de freio, assentos e acessórios como compartimentos para objetos. São comumente prescritos para pessoas com bom nível de funcionalidade, que precisam de mínimo suporte ao peso corporal.

Figura 1 - Principais configurações de andadores

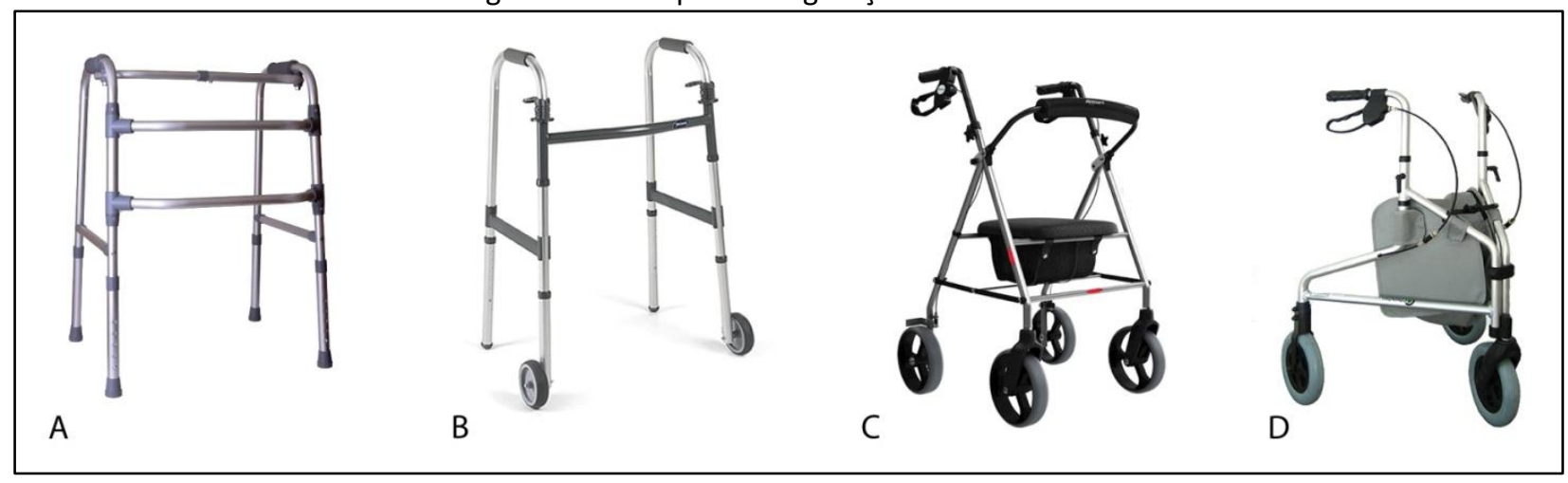

Fonte: Adaptado de Medjet, Mundo Geriátrico, Mercur e Vivere (2018) 
O Sistema Único de Saúde (SUS) brasileiro possibilita a aquisição de andadores de estruturas fixas ou articuladas, com regulagem de altura, manoplas em borracha ou espuma recoberta e quatro ponteiras fixas de borracha (BRASIL, 2018).

Além dos andadores convencionais, na literatura científica podem ser encontradas referências a duas categorias inovadoras de andadores: os smart walkers e os lift assist walkers. Os primeiros são equipamentos com estrutura semelhante a dos andadores convencionais, que incluem recursos de eletrônica ou robótica. De acordo com Alves et al. (2016), a pesquisa e o desenvolvimento desses dispositivos se propõe a melhorar a sua manobrabilidade, promover padrões de marcha mais naturais e a reduzir riscos, como as quedas relacionadas ao uso de andador.

A fim de atender demandas de públicos-alvo específicos, os atributos dos smart walkers perpassam diferentes ordens de funcionalidades. Nas principais bases de dados podem ser encontrados projetos com recursos de monitoramento de saúde, assistência cognitiva e sensorial além de aprimoramentos eletrônicos ou mecânicos que visam dar maior suporte físico; e recursos de interface direta ou indireta para aperfeiçoar a interação homem-máquina (ALVES ET AL., 2016).

De acordo com Bulea \& Triolo (2012), os lift assist walkers são uma classe de andadores advinda de dificuldades na realização de manobras de transferência entre as posturas sentada e em pé, que parte do público com mobilidade reduzida apresenta. Incluem-se nessa categoria os andadores com aprimoramentos mecânicos ou componentes eletrônicos, empregados para oferecer maior suporte, independência e segurança na execução das manobras. Alguns modelos disponíveis para compra atualmente são o StandUp Walker (fig.2 A), o Hugn'Go ${ }^{4}$ (fig.2 B) e o EVA Support, produzido na versão pneumática ${ }^{5}$ (fig.2 C) e na versão elétrica ${ }^{6}$ (fig.2 D).

Figura 2 - Lift assist walkers

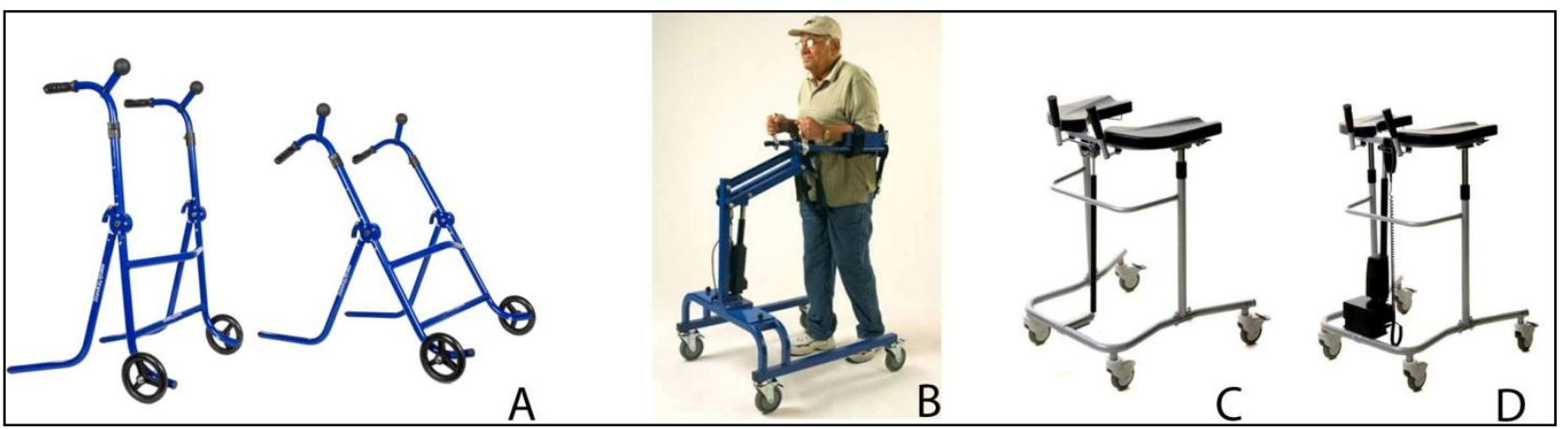

Fonte: adaptado de U Rise Products, Able Data e Medical Products (2018)

A partir dos critérios de Alves et al. (2016), os lift assist walkers que contêm componentes eletrônicos - como uma das alternativas do EVA Support - podem também ser considerados smart. É possível, também, encontrar em periódicos científicos os andamentos de projetos ainda mais complexos de smart walkers com recursos para auxílio à transferência, como os de Kawazoe

\footnotetext{
${ }^{3}$ Ver em: https://www.uriseproducts.com/

${ }^{4}$ Ver em: http://www.abledata.com/product/hugn-go-models-100-200-350

${ }^{5}$ Ver em: https://www.medicalproductsdirect.com/evasuwapnad.html

${ }^{6}$ Ver em: https://www.medicalproductsdirect.com/evaelsupwalc.html
} 
et al. (2017) (fig.3 A), Yuk et al. (2013) (fig.3 B) e Bulea \& Triolo (2012) (fig.3C).

Figura 3 - Projetos de smart walkers com função de auxílio à transferência postural

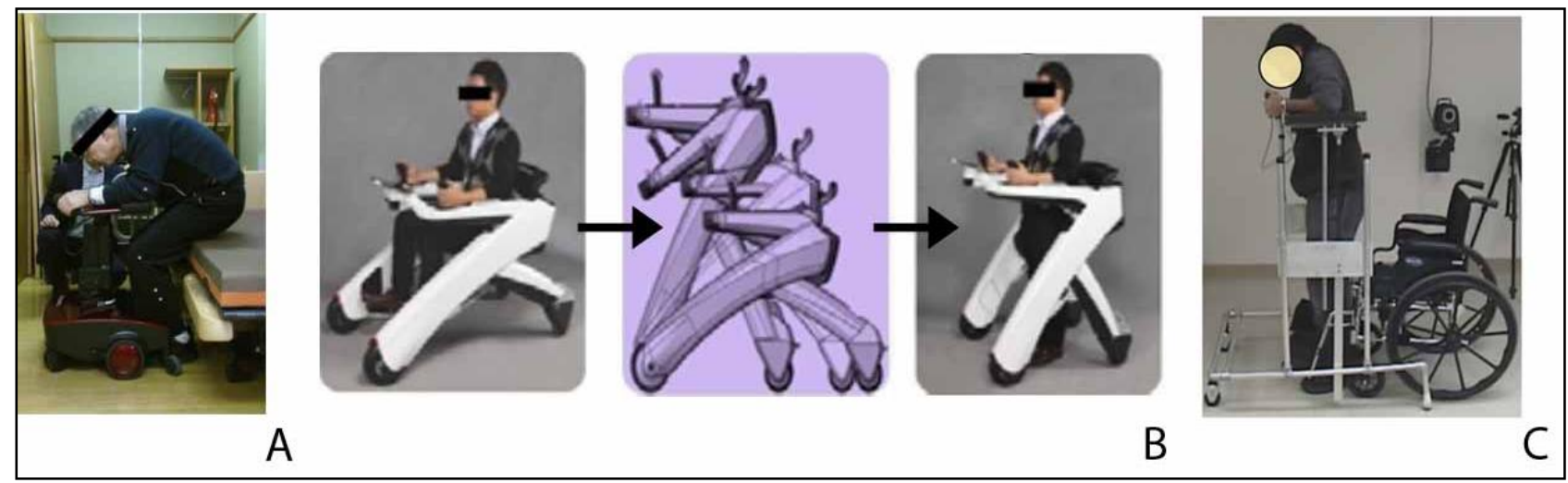

Fontes: adaptado de Kawazoe et al. (2017); Yuk et al. (2013) e Bulea \& Triolo (2012)

\subsection{Design e Tecnologia Assistiva}

De acordo com a CIF, quando um fator ambiental favorece o desempenho de um indivíduo, é compreendido como um facilitador. Em contraponto, quando reduz seu desempenho, é compreendido como uma barreira (WHO, 2002).

Victor Papanek, um dos mais importantes pensadores sobre o papel exercido pela atividade do design, escreveu que o propósito fundamental do design é o de transformar o ambiente e as ferramentas da humanidade e, por extensão, transformar a humanidade em si (1973). Nesse processo dinâmico de criação e transformação, podemos compreender a prática do design como produtora de facilitadores - e de barreiras - à funcionalidade.

Papanek defende que, para atender as demandas reais das pessoas, a atividade requer responsabilidade social e moral. Falar em demandas no contexto da Tecnologia Assistiva, no geral, remete à necessidade de mitigar deficiências ou restrições de funcionalidade. $O$ processo de design tende a seguir uma lógica de solução de problemas, semelhante à cultura de diagnóstico e cura do modelo médico de incapacidade, mencionado na seção anterior. A humanidade, no entanto é formada por indivíduos complexos, com dadas características fisiológicas e psicológicas, e que estão inseridos em determinados contextos físicos e sociais. Para que haja responsabilidade no processo projetual, deve haver uma investigação atenta em relação a quem essas pessoas são, o que necessitam, desejam, em que contexto estão, como interagem com esse contexto... do contrário, a tendência é a criação de produtos irrelevantes, descartáveis, e/ou que funcionam como barreiras - sejam elas físicas, sociais ou psicológicas.

\section{Metodologia}

Diante do exposto, o delineamento estabelecido para esse trabalho foi o estudo de campo que, de acordo com Gil (2002, p.53), é um modelo de pesquisa "desenvolvida por meio da observação direta das atividades do grupo estudado e de entrevistas com informantes para captar suas explicações e interpretações do que ocorre no grupo".

O estudo foi feito em uma instituição de referência em assistência social, saúde e educação, situada na cidade de Niterói, Rio de Janeiro. Foram adotados procedimentos 
qualitativos para levantamento e análise dos dados. Os procedimentos de levantamento das informações foram as entrevistas individuais semiestruturadas e as observações não participantes.

As entrevistas costumam ser feitas a partir de um roteiro estabelecido previamente, para tratar das questões pertinentes à pesquisa. $O$ caráter semiestruturado do roteiro expressa que as perguntas são abertas, para que os participantes contribuam com suas experiências e opiniões pessoais; e que a aplicação das perguntas é feita de maneira flexível, conforme os relatos vão emergindo. Isso possibilita que se aprofundem determinados assuntos ou que se evite que questionamentos se repitam, o que tende a acontecer em entrevistas de caráter estruturado (CRESWELL, 2007; MARCONI \& LAKATOS, 2003; GIL, 2002).

As observações são procedimentos básicos na investigação qualitativa. Não se tratam de simplesmente presenciar situações, mas de examiná-las a partir das questões que se relacionam com a pesquisa. O caráter não participante expressa que os pesquisadores não se envolvem nas situações observadas, mas são expectadores críticos. O procedimento pode revelar questões interessantes não previstas e mesmo comportamentos e fenômenos envolvidos, que os informantes não considerariam relevantes para uma narrativa, não saberiam informar ou nem mesmo têm consciência de que acontecem (CRESWELL, 2007; MARCONI \& LAKATOS, 2003; GIL, 2002).

Os procedimentos de levantamento de dados foram aplicados em cinco visitas técnicas, realizadas durante sessões de reabilitação nos setores de fisioterapia neurofuncional e reumatotraumato-ortopédica da instituição. Participaram da pesquisa sete profissionais de reabilitação e sete pacientes, todos atendidos pelo SUS. Nas visitas foi feita a apresentação da proposta de pesquisa e dos termos livres de consentimento, que foram assinados pelo pesquisador responsável e pelos participantes. Com a devida autorização, foram feitas fotografias, gravações de áudio e vídeos para análise posterior.

Dois roteiros de entrevistas semiestruturadas foram elaborados: (1) o modelo de entrevista com os usuários contemplou a experiência de uso do andador, com perguntas sobre conforto e segurança, execução de diferentes manobras, atividades de vida diária e uso de outros dispositivos de TA; e (2) o modelo de entrevista com os profissionais, por sua vez, contemplou assuntos como indicações e treinamento do uso de andadores, além de relatos de experiências dos pacientes com os dispositivos. As observações aconteceram durante a realização das entrevistas e das sessões de reabilitação e treinamento com os andadores. Foi prestada atenção à execução da marcha e de manobras de transferência; às instruções dos profissionais e às técnicas empregadas nas diferentes situações; à simulação de atividades de vida diária e de passagens por barreiras físicas; bem como outros possíveis aspectos da interação com o andador.

Optou-se pela análise qualitativa do conteúdo, conforme sugerido por Gil (2002), com a redução dos dados coletados em campo; criação de categorias e organização dos dados a partir delas; interpretação; e, finalmente, redação dos resultados, apresentados na seção que segue. Para preservar a identidade dos informantes, optou-se pelo uso das letras iniciais dos nomes para atribuir às falas.

\section{Resultados e Discussão}

Durante a realização das entrevistas, todos os profissionais relataram reclamações dos pacientes em relação a alguns componentes do andador, em especial às manoplas, que tendem a 
se deteriorar com o contato constante com as mãos, e às ponteiras, que se desgastam a ponto de comprometer a segurança do usuário por falta de atrito com o chão. A fala de R. ilustra como a configuração das manoplas pode ser fonte de desconforto físico, que é capaz de influenciar negativamente experiência de uso do equipamento como um todo: "Alguns reclamam dessa pega. Quando é mais acolchoadinha, rasga, aí depois o contato fica só a mão no ferro. Ou é uma borracha mais dura e eles sentem um desconforto porque o material não tem nenhuma espécie de deformação. Não acomoda em nada o punho".

R. pontuou que a sensação do contato da pele com o metal pode ser desagradável, especialmente em ambientes com ar condicionado como a sala de reabilitação. K.A., por sua vez, disse que o contato direto e intenso com o metal pode fazer lesões na pele e até prejudicar a estabilidade. P. adicionou à fala dos colegas, mencionando que as poucas possibilidades de variação de pega, oferecidas pela disposição bilateral das manoplas, pode gerar lesões inflamatórias, como tendinites ou bursites.

A recorrência de queixas dos pacientes em relação ao desgaste das ponteiras traz à luz uma importante demanda relacionada à segurança. A fala da fisioterapeuta A. representa a necessidade da atenção dos usuários à manutenção dos equipamentos, e questões de responsabilidade em aspectos da produção dos andadores: "Eles reclamam que as ponteiras ressecam com muita facilidade e, dependendo da marca, algumas não são bem fixadas. Vêm um pouco frouxas e acabam caindo, se perdendo".

Alguns modelos de andadores possuem sistemas de ajuste de altura e de fechamento com pinos. Os profissionais expuseram preferências e dificuldades que os usuários costumam relatar, como o referido por A.: "Alguns reclamam que é muito duro e sentem dor no dedo quando apertam o pino. Quando tem capinha protetora, ajuda e não machuca. Eles também preferem o modelo que tem só um pino central na barra da frente, que aperta e fecha os dois lados. Com o andador que tem um pino em cada lateral, eles têm mais dificuldade".

P., que trabalha no setor neurofuncional destacou que, além do aspecto físico, alterações sensoriais e cognitivas interferem na interação com os sistemas de fechamento e ajuste: "Às vezes o paciente não consegue fechar o andador. Não consegue identificar o pinozinho para fechar, para regular. O botão é pequeno, e quando o paciente é mais idoso, tem problema de vista ou até um certo grau de dificuldade cognitiva, até eles acharem aquele pino... Você até ensina, mas alguns deles acham muito difícil".

Cabe ressaltar a importância da simplicidade dos diferentes aspectos de uso de um dispositivo assistivo como o andador. Parte significativa do público-alvo é de pessoas idosas e/ou que se reabilitam de condições neurológicas. A senescência leva a uma redução natural na percepção sensorial, que tende a dificultar a visualização e o manejo de objetos pequenos. Atributos cognitivos também tendem a ser alterados, o que pode gerar dificuldades de assimilação de informações complexas (BICALHO \& CINTRA, 2013; MORAES \& CINTRA, 2013). Quando patologias atingem o sistema nervoso central e periférico, esse tipo de dificuldade pode se tornar incapacidade. $\mathrm{O}$ projeto de sistemas mais acessíveis pode permitir que alguns desses pacientes consigam interagir com o dispositivo com maior independência, autonomia e facilitar a incorporação do objeto à rotina do indivíduo.

Ainda em relação ao ajuste, alguns profissionais revelaram que os andadores não acomodam pacientes de estaturas extremas. A. relatou que já fez requisição de um modelo 
infantil para uma paciente idosa, que tinha menos de um metro e meio de altura. Considerando que os idosos estão entre os principais usuários de andadores, e que a senescência leva à redução de estatura devido a processos naturais como os desgastes nos tecidos ósseo e cartilaginoso e encurtamento de fibras musculares (BICALHO \& CINTRA, 2013), pode ser que haja uma discrepância entre o dimensionamento dos produtos disponíveis e as características de parte importante do seu público-alvo. Ainda que alguns modelos infantis se assemelhem aos de adulto, esse tipo de situação faz compreensíveis alguns constrangimentos e até resistências ao uso.

No caso de pessoas mais altas, o andador mais baixo força uma postura encurvada, que pode gerar dores e mesmo lesões osteoarticulares. A. contou que alguns pacientes aumentaram os tubos internos dos seus andadores por conta própria, já que a instituição de reabilitação não faz esse tipo de adaptação. É possível que a necessidade de adaptações - especialmente quando feitas por pessoas sem especialização em dispositivos assistivos - possa vir a comprometer a estabilidade e a segurança do equipamento.

Os pacientes entrevistados disseram que não alteraram as alturas dos seus andadores depois de os fisioterapeutas terem feito os ajustes. Foi observado o momento de regulagem para que a paciente $\mathrm{C}$. fizesse sua primeira experiência usando o andador. A fisioterapeuta K. posicionou o dispositivo deitado sobre uma das plataformas da sala de reabilitação, como pode ser visualizado na figura 4. Por acaso, quando a profissional levantou, atrapalhou-se com as pernas do andador e bateu a cabeça na estrutura. Os comentários dos entrevistados, somados à situação presenciada, parecem indicar algumas possibilidades de aprimoramento em relação aos componentes e a como se dá a tarefa de ajuste.

Figura 4 - Fisioterapeuta fazendo ajuste de altura do andador

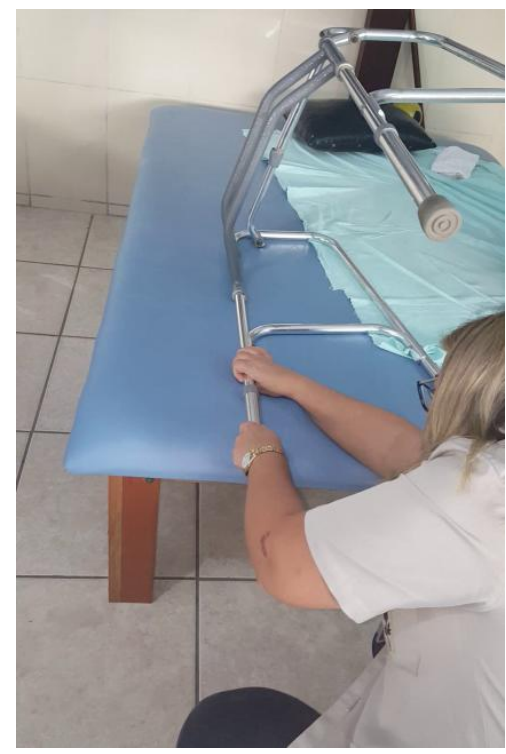

Fonte: o autor

Em relação ao desempenho em AVDs com o uso do andador, os pacientes entrevistados não relataram maiores dificuldades em atividades básicas de vida diária (ABVDs). Em sua fala, o usuário C.G. ressaltou os ganhos de independência e privacidade no que diz respeito às capacidades de marcha, transferência e às atividades de autocuidado e higiene pessoal: "Dentro 
de casa me dá uma liberdade muito grande e alivia um pouco a minha família".

Para banharem-se, os usuários são instruídos a deixar o andador do lado de fora do box. Alguns, como C.G., que tem problemas de equilíbrio, fazem uso de cadeira de banho. Outros disseram que conseguem tomar banho em pé. Pessoas com maior poder aquisitivo podem, ainda, adicionar barras de segurança e assentos retráteis ao banheiro, mas esse tipo de adaptação não é comum entre as pessoas atendidas na instituição. De acordo com os profissionais, alguns pacientes têm banheiros tão pequenos em casa que nem conseguem entrar com $o$ andador. Movimentam-se, segurando nas paredes e superfícies.

O banheiro é um dos cômodos da casa com mais fatores de risco de queda. Revestimentos escorregadios, tapetes soltos, banheiras, superfícies molhadas e desníveis, como os que comumente delimitam a área do box, aumentam significativamente a prevalência de escorregamentos e tropeços. É preocupante a necessidade de largar um dispositivo de assistência à mobilidade, especialmente para entrar em um ambiente adverso.

A realização de atividades instrumentais de vida diária (AIVDs) depende do grau de comprometimento da mobilidade do paciente, mas também de aspectos culturais e individuais. Mulheres têm mais tendência a realizar as atividades de cuidado doméstico do que os homens, por exemplo. O senhor F., por sua vez, revelou pró-atividade, independência e notável consideração pelo papel do seu andador no desempenho das tarefas: "Eu moro sozinho, né? Aí fico o dia todo me movimentando com ele. Dá pra fazer as atividades de casa tranquilo. Lavar roupas, fazer comida, varrer, passar a máquina [de cortar grama] no quintal... Um conserto que às vezes tem que fazer, uma pintura, que eu pretendo fazer qualquer dia...".

Figura 5 - Paciente F. fazendo treino de marcha no circuito que simula situações cotidianas

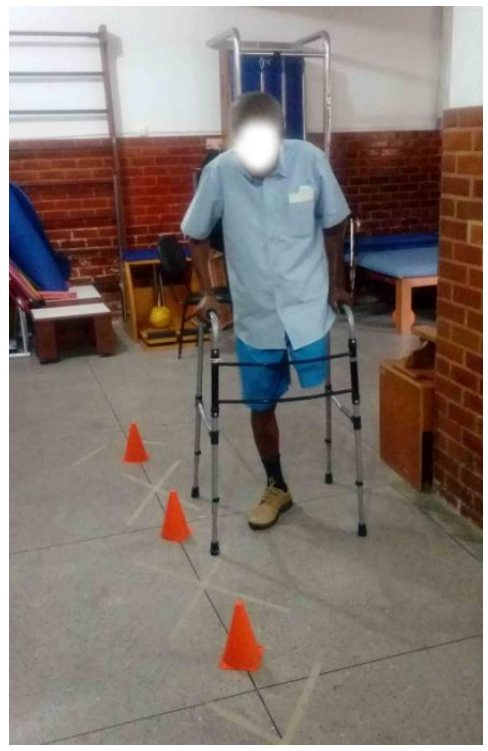

Fonte: o autor

Entretanto, a realização de AIVDs é mais fácil quando se restringe ao ambiente doméstico. F. diz que tem incentivos da filha para que saia mais de casa, mas a rua onde mora é muito irregular, então ele prefere ir até o quintal, no máximo. 
Os entrevistados revelaram a importância de contar com outras pessoas para realização de tarefas ou para acompanhar os pacientes, e a necessidade de outros tipos de TA no ambiente externo. C.G., por exemplo, revelou que se as ruas fossem mais acessíveis, usaria andador. Por ora, ele precisa de outros meios para se locomover com segurança e conforto: "Quando eu vou pra rua, eu não vou com o andador. O andador foi indicado pra usar em casa, ou em algum lugar que não tenha desvios. Pra descer o morro eu uso a muleta, e depois vou com a cadeira de rodas porque fica muito puxado. Não consigo ir muito longe com o andador".

Os profissionais relataram que a inadequação do contexto urbano restringe muito a mobilidade dos usuários de andadores, e coloca em risco aqueles que tentam "se aventurar", como pontuou o fisioterapeuta R.: "Tem paciente que tem recomendação de utilizar o andador em casa, aí quer pegar pra andar lá fora, tropeça e cai. A queda acontece quando o paciente quer ir um pouco além daquilo que dá pra fazer".

O fisioterapeuta P. contou que, além da experiência profissional, tem alguém próximo que usa andador. Ele somou ao coro dos usuários que dizem que as dimensões dos dispositivos são empecilhos para transporte, armazenamento e que isso gera incômodos para usuários e acompanhantes: "A gente passa o maior sufoco na hora que tem que colocar o andador na mala do carro, porque é um andador desses, tamanho único, então é muito ruim! Se desse para compactar, articular ele, conseguir fechar melhor... Seria muito importante!".

A dificuldade de mobilidade no ambiente externo leva a restrições na execução de atividades avançadas de vida diária (AAVDs), na independência e, muitas vezes, na autonomia daquele indivíduo. Por exemplo, P. assinalou restrições no acesso a agências bancárias. Quando outras pessoas passam a assumir atividades que envolvem administração de dinheiro no lugar da pessoa idosa, com deficiência ou mobilidade reduzida, decisões importantes em relação ao uso de seus recursos e à própria vida podem ser desconsideradas. Como R. explicou, o uso do dispositivo tem seu objetivo específico: "O andador te permite ficar de pé, te dá certa estabilidade, mas o foco dele não é dar mobilidade. É te colocar de pé e te dar uma maneira de fazer uma marcha e de ser, de alguma forma, mais independente".

As informações compiladas em campo revelaram que os andadores somam em algum grau à mobilidade e à independência do usuário, especialmente no que concerne à execução de ABVDs e AIVDs dentro do ambiente doméstico. Conforme as atividades vão ficando mais complexas, são percebidos menores ganhos. Ainda, quando associadas a ambientes físicos desfavoráveis, algumas características do andador podem até agir como barreiras à participação e atividade daquele indivíduo, ou colocá-lo em situações de risco.

\section{Conclusão}

As pesquisas bibliográficas e de campo revelaram que modelos de andadores com as mesmas características são utilizados para atender às necessidades de pessoas com condições de saúde que perpassam patologias neurológicas, deficiências ortopédicas, doenças cardiovasculares, entre outras. O público-alvo dos andadores é, portanto, absolutamente diverso e cresce exponencialmente em número e em diversidade - não apenas no que concerne estruturas e funcionamentos fisiológicos, mas também em termos do que caracteriza essas pessoas como indivíduos em uma sociedade complexa, como idade, gênero, cultura, características psicológicas, cognitivas, comportamentos e atitudes, além dos contextos físicos e sociais em que estão inseridos. 
A intenção de projetar ou disponibilizar um produto com propósito de atender às demandas do maior número de pessoas possível, passando por cima de tamanha diversidade, pode levar ao imperativo de uso de algo que não atenda satisfatoriamente a parte significativa desse grupo. Diante disso, algumas pessoas têm que adquirir outros produtos de Tecnologia Assistiva, depender de cuidadores, restringir suas rotinas, e até o seu potencial de reabilitação. Entre os caminhos possíveis para mudança da atual conjuntura, estão projetos que sirvam como alternativas de consumo e uso, sejam eles novas categorias de Tecnologia Assistiva mais alinhadas às especificidades de grupos dentro desse contingente maior ou dispositivos que possam ser personalizados, por exemplo. Essas são sugestões que tendem, sim, a significar aumento de custos de projeto e distribuição, mas que podem também representar ganhos em termos de econômicos e de saúde pública (dispositivos mais adequados significam menos dependência, menor incidência de acidentes evitáveis, reduções de gastos com reabilitação de condições de saúde associadas a esses acidentes, menos internações, etc.), e mesmo serem convertidos em oportunidades não exploradas de mercado e inovação, especialmente se ponderarmos sobre o que dizem as tendências demográficas em relação ao aumento do percentual de pessoas idosas, com mobilidade reduzida e/ou deficiências.

Dessa variedade de público também advém a necessidade de amplo treinamento, com particularidades de uso para cada caso. Quando o indivíduo sai - consciente ou inconscientemente - dos limites instruídos pelos profissionais de reabilitação, ele pode se colocar em situações de risco. A pesquisa de campo revelou que os ganhos em mobilidade, funcionalidade e independência se limitam às atividades mais básicas de vida diária. Sendo o ser humano social e complexo, qual a possibilidade de conformidade diante da possibilidade de performance em tarefas restritas à sobrevivência e ao cuidado da casa?

A lógica pela qual tem se dado o desenvolvimento de Tecnologia Assistiva se assemelha ao paradigma médico, de diagnóstico e tratamento de condições de saúde, em uma cultura que desloca o foco do indivíduo para as deficiências a serem mitigadas, e que resulta em produtos projetados para uso em condições e contextos controlados. A essência do paradigma biopsicossocial se assemelha à da atividade do design, que idealmente tem início com investigação das características do público a que se destinam as soluções. A observação holística de quem são, onde vivem, quais as necessidades e motivações do público decerto levará a soluções que favoreçam a interação com o produto, a performance em atividades de vida diária que são relevantes para essas pessoas e a experiências de uso mais positivas e seguras. 


\section{Referências}

ALVES, J.; et al. Considerations and mechanical modifications on a Smart Walker. In: International Conference on Autonomous Robot Systems and Competitions. 2016. p. 247-252.

ASSIS, M. G.; ASSIS, L. O.; CARDOSO, A. P. Reabilitação das atividades diárias. In: MALLOY-DINIZ, F.I.; FUENTES, D.; COSENZA, R. M. Neuropsicologia do Envelhecimento: Uma Abordagem Multidimensional. Porto Alegre: Artmed, 2013. p. 360-377.

BATENI, H.; MAKI, B. E. Assistive Devices for Balance and Mobility: Benefits, Demands and Adverse Consequences. Arch Phys Med Rehabil. vol. 86, p. 134-145, jan. 2005.

BICALHO, M. A. C.; CINTRA, M. T. G. Modificações Fisiológicas Sistêmicas no Envelhecimento. In: MALLOY-DINIZ, F.I.; FUENTES, D.; COSENZA, R. M. Neuropsicologia do Envelhecimento: Uma Abordagem Multidimensional. Porto Alegre: Artmed, 2013. p. 78-99.

BRADLEY, S. M.; HERNANDEZ, C. R. Geriatric Assistive Devices. American Family Physician. vol.84, num. 4. p. 405-411, aug. 2011.

CARVALHO, J. A. Órteses: um recurso terapêutico complementar. 2. ed. Barueri: Manole, 2013.

CRESWELL, J. W. Projeto de Pesquisa: Métodos qualitativo, quantitativo e misto. 2. ed. Porto Alegre: Artmed, 2007.

BRASIL. Ministério da Saúde. Sistema de Gerenciamento da Tabela de Procedimentos, Medicamentos e OPM do SUS. In: DATASUS, 2018 (http://sigtap.datasus.gov.br/tabelaunificada/app/sec/procedimento/exibir/0701010010/03/2018)

. Subsecretaria Nacional de Promoção dos Direitos Humanos da Pessoa Com Deficiência. Comitê de Ajudas Técnicas. Tecnologia Assistiva. Brasília: CORDE, 2009.

KAWAZOE, S. ET AL., Development of Standing Assistive Walker for Domestic Use. In: IEEE International Conference on Industrial Technology. Toronto, 22-25 march. 2017 p. 1455-1460.

GIL, A. C. Como elaborar projetos de pesquisa. 4. ed. São Paulo: Atlas, 2002.

MARCONI, M. A.; LAKATOS, E. M. Fundamentos de Metodologia Científica. 5.ed. São Paulo: Atlas, 2003.

MARTINS ET AL., Assistive mobility devices focusing on Smart Walkers: Classification and review. Robotics and Autonomous Systems. vol.60, p. 548-562, 2011.

MORAES, E. N.; CINTRA, M. T. G. Avaliação Geriátrica. In: MALLOY-DINIZ, F.I.; FUENTES, D.; COSENZA, R. M. Neuropsicologia do Envelhecimento: Uma Abordagem Multidimensional. Porto Alegre: Artmed, 2013. p. 297-322.

PAPANEK, V. Design for the Real World. New York: Bantam, 1973.

PHILLIPS, B.; ZHAO, H. Predictors of Assistive Technology Abandonment. Assistive Technology. vol.5. p. 36-45. 1993.

WORLD HEALTH ORGANIZATION. Global Disability Action Plan 2014-2021: Better Health for All People with Disabilities. Geneva, 2015. 
. Towards a Common Language for Functioning, Disability and Health: ICF. In: World Health Organization, 2002. (http://www.who.int/classifications/icf/icfbeginnersguide.pdf) World Report on Disability. Geneva, 2011.

. World Report on Ageing and Health. Geneva, 2015b.

VAN HOOK, F. W.; DEMONSBREUN, D.; WEISS, B. D. Ambulatory Devices for Chronic Gait Disorders in the Elderly. American Family Physician, vol. 67, n.o 8, p. 1717-1724. abr 2003.

YUK, G. ET AL. Smart walker development based on experts' feedback for elderly and disabled. $10^{\text {th }}$ International Conference on Ubiquitous Robots and Ambient Intelligence (URAI). Oct. 31Nov.2, 2013. 